Research Article

\title{
Mechanical Behavior Analysis of Y-Type S-SRC Column in a Large-Space Vertical Hybrid Structure Using Local Fine Numerical Simulation Method
}

\author{
Jianguang Yue \\ College of Civil Engineering, Nanjing Tech University, Nanjing 211800, China \\ Correspondence should be addressed to Jianguang Yue; jgyue@njtech.edu.cn
}

Received 9 January 2018; Revised 7 March 2018; Accepted 11 March 2018; Published 2 April 2018

Academic Editor: Estokova Adriana

Copyright (c) 2018 Jianguang Yue. This is an open access article distributed under the Creative Commons Attribution License, which permits unrestricted use, distribution, and reproduction in any medium, provided the original work is properly cited.

\begin{abstract}
In a large spatial structure, normally the important members are of special type and are the safety key for the global structure. In order to study the mechanical behavior details of the local member, it is difficult for the common test method to realize the complex spatial loading state of the local member. Therefore, a local-fine finite element model was proposed and a large-space vertical hybrid structure was numerically simulated. The seismic responses of the global structure and the Y-type S-SRC column were analyzed under El Centro seismic motions with the peak acceleration of 35 gal and 220 gal. The numerical model was verified with the results of the seismic shaking table test of the structure model. The failure mechanism and stiffness damage evolution of the Y-type S-SRC column were analyzed. The calculated results agreed well with the test results. It indicates that the local-fine FEM could reflect the mechanical details of the local members in a large spatial structure.
\end{abstract}

\section{Introduction}

The spatial structures have been widely used in gymnasium, exhibition center, airport terminal, railway station, high-rise building, and bridge structures in China [1]. From the last century, some kinds of the spatial structures had been developed and researched deeply, including the thin-shell structure, cable structure, and space-truss structure. Till now, some modern spatial structures, such as the cablemembrane structure, beam string structure, and suspendeddome structure, will further promote the design theory and construction technique for the spatial structure system. Therefore, the mechanical performance of the complex structures and new members has become the research focus.

In this paper, the mechanism of a vertical hybrid structure of beam string roof and RC frame was analyzed. In this structure, a Y-type-steel steel-reinforced concrete column (Y-type S-SRC column) was used to strengthen the stiffness of the roof. The Y-type S-SRC column supports the roof by two slant steel pipe columns and transmits the loads to the ground by SRC column. Thus, the Y-type S-SRC column, which bears complex loads, is very important to ensure the safety of the roof and the whole structure. Lu [2] studied the seismic performance of this hybrid structure and analyzed the mechanical behavior of the Y-type S-SRC column through the static loading test. There are some similar experimental researches, for example, Fang et al. [3] studied the mechanical behavior of the steel-beam-SRC-column joint and RC-beam-circle-steel-pipe-column joint. Although the experiment is a good method to study the member's mechanical behavior, the actual loading and boundary conditions of the members are very difficult to be realized in the experiments for the limitations of experimental equipment. Therefore, there are some differences between the experiments and the realities of the load bearing states of the spatial member.

In a real structure, the loading and boundary conditions of the spatial member changes hand in hand with the responses of the whole structure. Similarly, in a finite element model of a structure, the mechanical responses of a member change synchronously with the global structure. It indicates that the FEM can simulate the loading and boundary conditions of the local member in a global structure. Obviously, it makes up some limitations of the test. Based on this understanding, this paper 


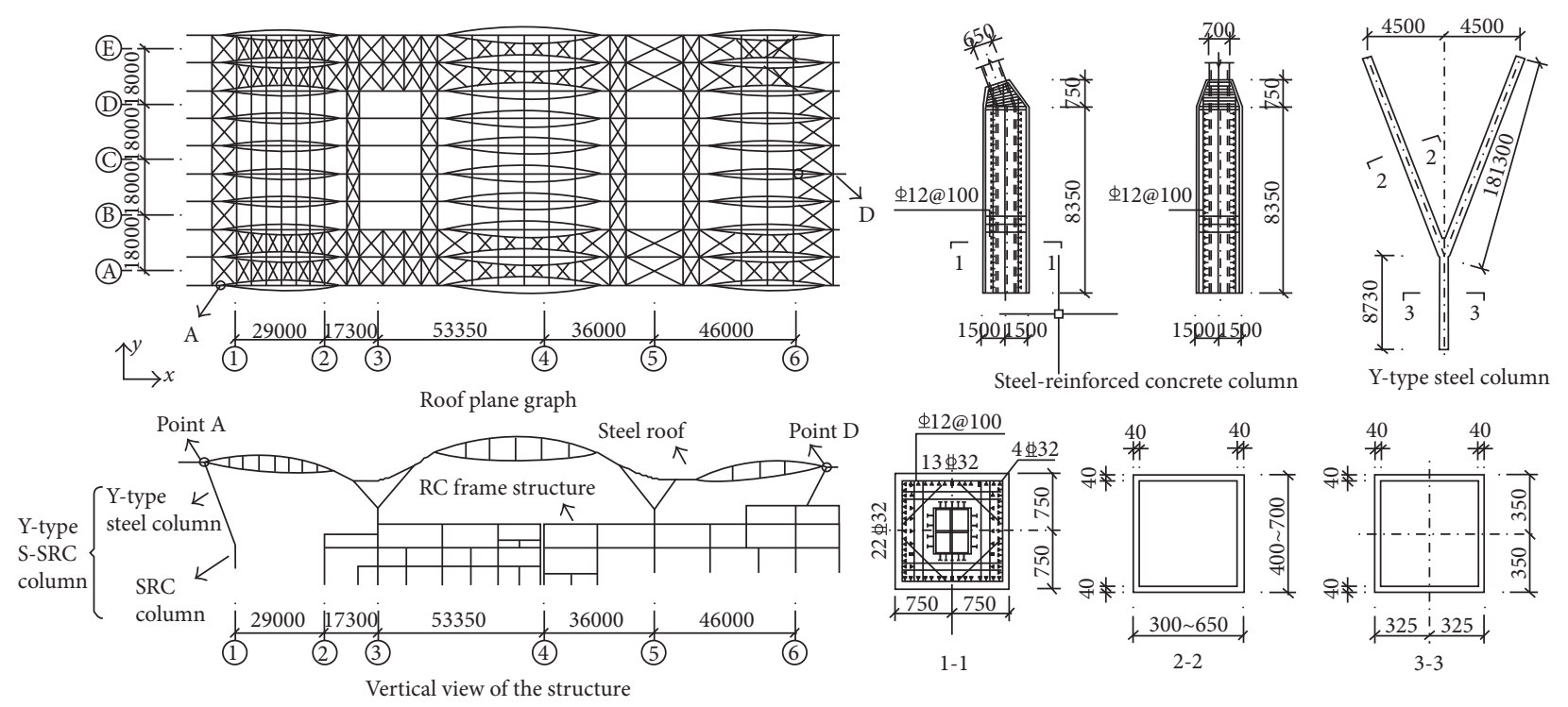

FIgURE 1: Draft of the structure and details of the Y-type S-SRC column.

studies the mechanical behavior of the Y-type S-SRC column by a local-fine finite element model. According to some experimental research results [2], the damage mechanism and stiffness damage of this type of column were analyzed in this paper.

\section{The Vertical Hybrid Structure}

This vertical hybrid structure (Figure 1), with the longitudinal span of $181.65 \mathrm{~m}$ and horizontal span of $64 \mathrm{~m}$, consists of three-part continuous beam string roof and RC frame structure. The roof system includes the roof beams, box steel beams, I-type beams, and braces. At the axis 1 (Figure 1), the roof structure is supported by the Y-type S-SRC column. The top ends of the Y-type columns are hinged to the roof.

The details of the Y-type S-SRC column are shown in Figure 1. It consists of the Y-type steel tube and SRC column. The section width and height of the Y-type steel tube were $300-650 \mathrm{~mm}$ and $400-700 \mathrm{~mm}$, respectively. The section of the SRC column was $1500 \times 1500 \mathrm{~mm}^{2}$. The square section of the embedded steel tube was $650 \times 700 \mathrm{~mm}^{2}$.

The cross-sectional width of the beam string was from $300 \mathrm{~mm}$ to $1622 \mathrm{~mm}$ and the height was from $768 \mathrm{~mm}$ to $2288 \mathrm{~mm}$. The three spans of the continuous roof beam were $46.85 \mathrm{~m}, 89 \mathrm{~m}$, and $46.85 \mathrm{~m}$, respectively. The truss rod of the roof was the welded box tube with the width of $300 \mathrm{~mm}$ and height from $200 \mathrm{~mm}$ to $600 \mathrm{~mm}$. The bottom chord of the roof was the cable steel rod with the diameter from $100 \mathrm{~mm}$ to $180 \mathrm{~mm}$. The compressive strength of concrete was $19.1 \mathrm{MPa}$, and the elastic modulus of concrete was $32500 \mathrm{MPa}$. The yield strengths of steel reinforcements were $210 \mathrm{MPa}, 300 \mathrm{MPa}$, and $360 \mathrm{MPa}$, respectively.

As shown in Figure 2, the seismic behavior of the global structure model with $1: 35$ geometric scale parameter was tested on the shaking table [4]. The three-directional waves of El Centro seismic motion were used as the input of the shaking table test. The ratio of the input waves in the $x, y$, and $z$ directions was $1: 0.85: 0.65$. Two case results of the test

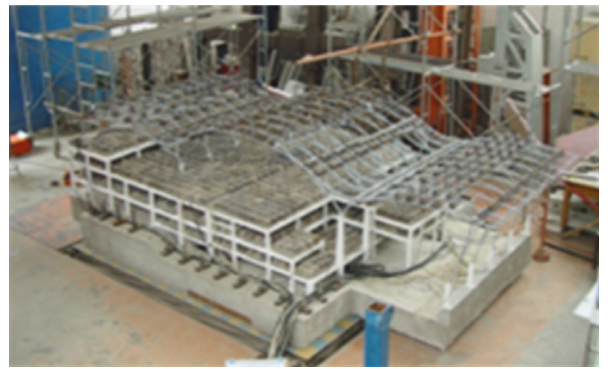

FIgURE 2: Experimental model of the structure [2, 4].

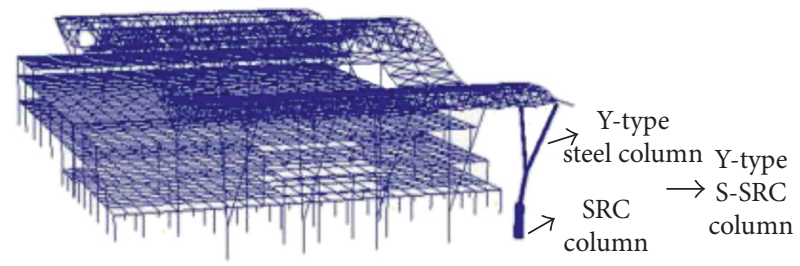

FIgURE 3: Finite element model.

$[2,4]$ were compared in this paper. In case 1 , the value of peak acceleration of the input wave was $35 \mathrm{gal}$. In case 2 , the value of peak acceleration of the seismic wave was 220 gal. More details about this experiment can be found in $[2,4]$.

\section{Local-Fine FEM}

There were a lot of members in the structure, so the global structure was better simulated by simple elements, such as beam elements and truss elements $[5,6]$. In order to capture the mechanical details of the Y-type S-SRC column, the Y-type S-SRC column in axis 1 was simulated by the local-fine FEM (Figure 3).

In this local-fine FEM of the column (Figure 3), the steel tube was modeled by the S4R elements, and the steel 
reinforcement was modeled by the T3D2 elements which were embedded in the concrete elements. The material behavior of steel was assumed as the ideal plastic-elastic model. The concrete was modeled by the C3D8R elements. The concrete behavior was described by the concrete plastic damage model in ABAQUS software [7]. The other SRC columns were simulated by the B31 elements, and the concrete material behavior was described by the smeared cracking constitutive model, in which the steel elements were coupled with the concrete elements. In the global structural FEM, the total element number was 71747 and the total number of nodes was 75285 .

\section{Material Behavior of the Confined Concrete}

The material behavior of the concrete in the SRC column was described by the stress-strain relation for the confined concrete and the plastic damage model. According to the modified method of the yield criterion and flow rule $[8,9]$, the second invariant stress ratio of the tensile and compression meridian plane is 0.725 , and the angle of dilatancy is $56.4^{\circ}$. Under monotonic loading, the stress-strain relation (Figure 4) of the confined concrete is described by the Mander model [10] as follows:

$$
\begin{gathered}
\sigma_{\mathrm{c}}=\frac{f_{\mathrm{cc}}^{\prime} \lambda\left(\varepsilon_{\mathrm{c}}^{\prime} / \varepsilon_{\mathrm{cc}}^{\prime}\right)}{\lambda-1+\left(\varepsilon_{\mathrm{c}}^{\prime} \varepsilon_{\mathrm{cc}}^{\prime}\right)^{\lambda}}, \\
\lambda=\frac{E_{\mathrm{c}}}{E_{\mathrm{c}}-\left(f_{\mathrm{cc}}^{\prime} / \varepsilon_{\mathrm{cc}}^{\prime}\right)},
\end{gathered}
$$

where $\sigma_{c}$ is the compressive stress of the concrete, $f_{c c}^{\prime}$ is the compression strength of the concrete, $\varepsilon_{\mathrm{c}}^{\prime}$ is the compressive strain, and $\varepsilon_{c c}^{\prime}$ is the compressive strain corresponding with $f_{\mathrm{cc}}^{\prime}$. The elastic modulus of the concrete was calculated by the following equation:

$$
E_{\mathrm{c}}=5000 \sqrt{f_{\mathrm{c}}^{\prime}}
$$

The compression strain $\varepsilon_{\mathrm{cc}}^{\prime}$ corresponding with $f_{\mathrm{cc}}^{\prime}$ of the unconfined concrete is calculated by the following equations:

$$
\begin{aligned}
& f_{\mathrm{cc}}^{\prime}=f_{\mathrm{c}}^{\prime}\left(-1.254+2.254 \sqrt{1+\frac{7.94 f_{l}^{\prime}}{f_{\mathrm{c}}^{\prime}}}-2 \frac{f_{l}^{\prime}}{f_{\mathrm{c}}^{\prime}}\right), \\
& \varepsilon_{\mathrm{cc}}^{\prime}=\varepsilon_{\mathrm{c}}^{\prime}\left(1+5\left(\frac{f_{\mathrm{cc}}^{\prime}}{f_{\mathrm{c}}^{\prime}}-1\right)\right), \\
& f_{l}^{\prime}=\frac{1}{2} K_{e} \rho_{\mathrm{s}} f_{\mathrm{yh}},
\end{aligned}
$$

and if the cross section is square,

$$
K_{e}=\frac{\left(1-\sum_{i}^{n}\left(\left(\omega_{i}^{\prime}\right)^{2} / 6 b_{\mathrm{c}} d_{\mathrm{c}}\right)\right)\left(1-s^{\prime} / 2 b_{\mathrm{c}}\right)\left(1-s^{\prime} / 2 d_{\mathrm{c}}\right)}{1-\rho_{\mathrm{cc}}},
$$

where $f_{l}^{\prime}$ is the compressive transverse confined press of the core concrete, $\varepsilon_{\mathrm{c}}^{\prime}$ is the compressive strain corresponding with the

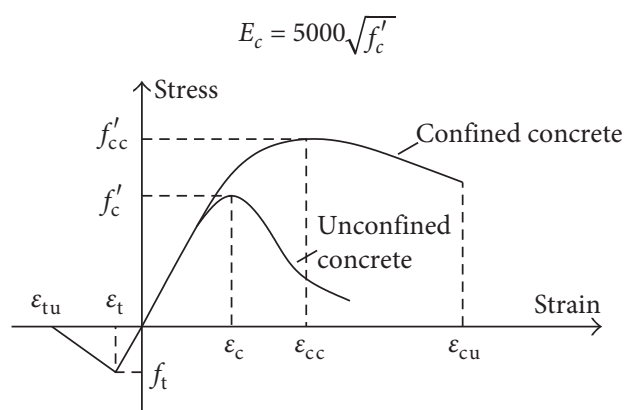

FIgURE 4: Stress-strain relations of the confined concrete.

TABLe 1: Comparisons of the structural dynamic behavior.

\begin{tabular}{lccc}
\hline Mode & 1 & 2 & 3 \\
& $T(\mathrm{~s})$ & $T(\mathrm{~s})$ & $T(\mathrm{~s})$ \\
\hline Calculated & 1.75 & 1.40 & 1.00 \\
Test [2] & 1.68 & 1.12 & 0.98 \\
\hline
\end{tabular}

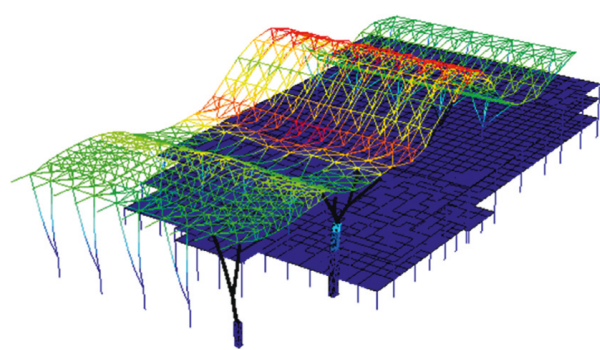

(a)

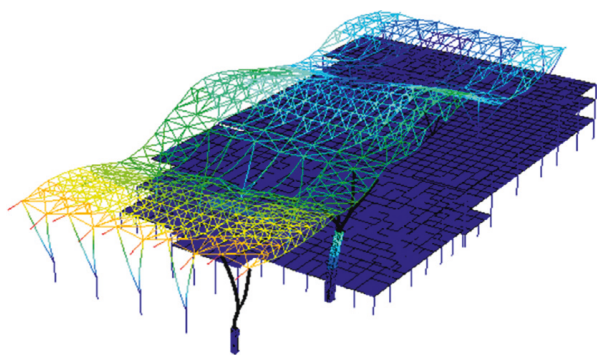

(b)

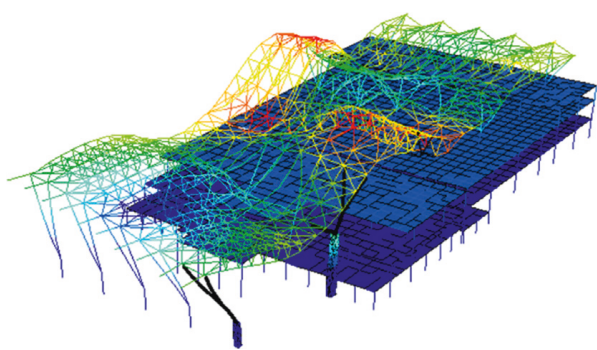

(c)

FIGURE 5: The calculated structural vibration modes. (a) The first vibration mode. (b) The second vibration mode. (c) The third vibration mode.

compressive strength $f_{\mathrm{c}}^{\prime}$ of the concrete, $f_{\mathrm{yh}}$ is the yield strength of the longitudinal reinforcement, $\rho_{\mathrm{cc}}$ is the reinforcement ratio, $n$ is the number of reinforcements, $b_{c}$ is the separation distance of the stirrup in the direction of the section width, $d_{c}$ is the 


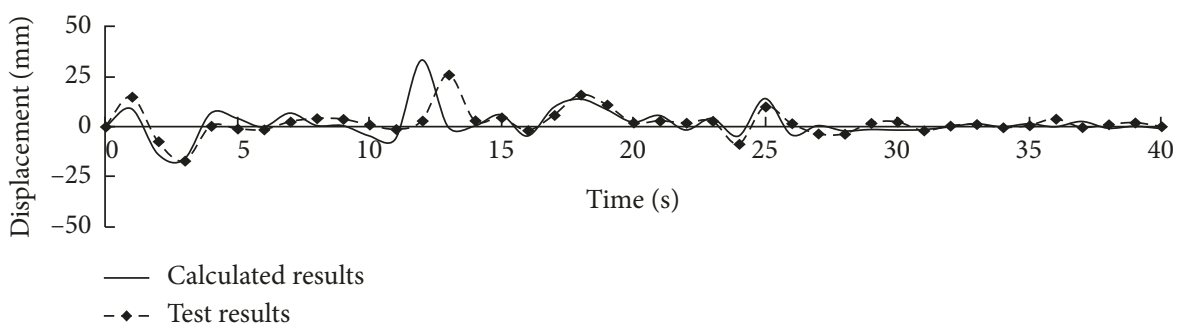

(a)

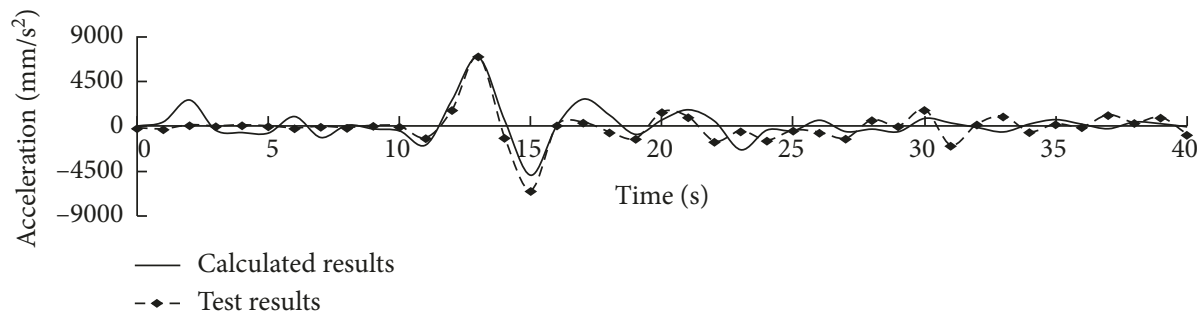

(b)

Figure 6: Comparisons of calculated and test results of case 2. (a) Displacement response of point D in the $y$ direction. (b) Acceleration responses of point $\mathrm{A}$ in the $y$ direction.

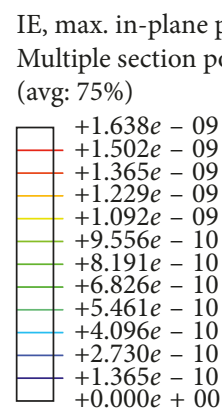

IE, max. in-plane principal Multiple section points (avg: 75\%)

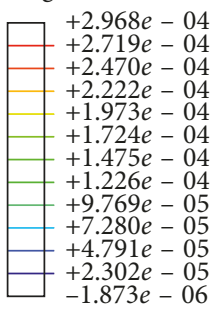

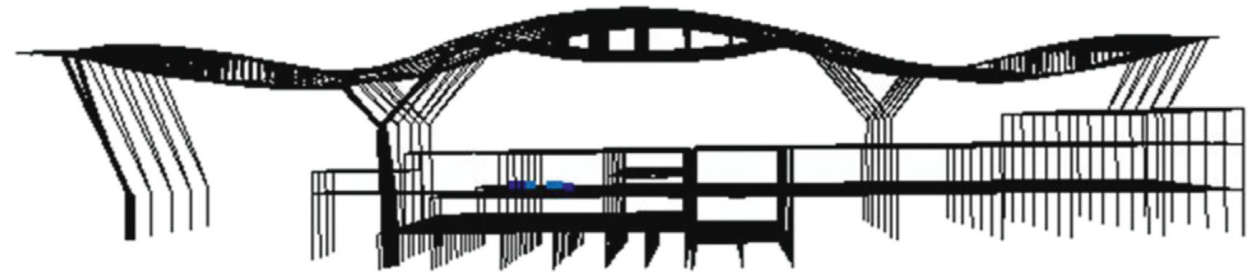

(a)

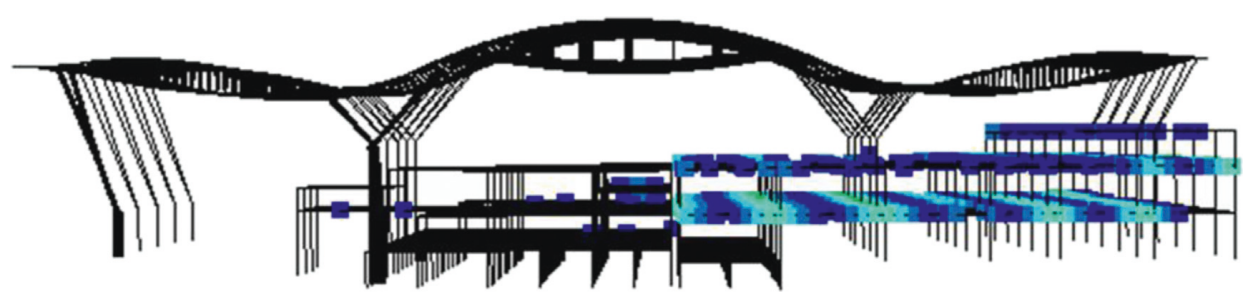

(b)

Figure 7: The damage states of the global structure: (a) case 1 and (b) case 2.

separation distance of stirrup in the direction of the section length, $\rho_{\mathrm{s}}$ is the stirrup ratio, $s^{\prime}$ is the clear space of the stirrup, and $d_{\mathrm{s}}$ is the separation distance of the stirrup on cross section.

\section{Seismic Responses of the Local-Fine FEM}

The calculated first three modes of the structure were compared with the test results in Table 1. The calculated first three vibration modes of the structure are shown in Figure 5. The first vibration mode is the translational motion of the global structure in the $x$ direction. The second vibration mode is the translational motion in the $y$ direction mixed with torsional motion of the global structure. The third vibration mode is the torsional motion of the roof. These characteristics of the vibration modes agree well with the test results $[2,4]$. 
S, Mises

Multiple section points (Avg: 75\%)

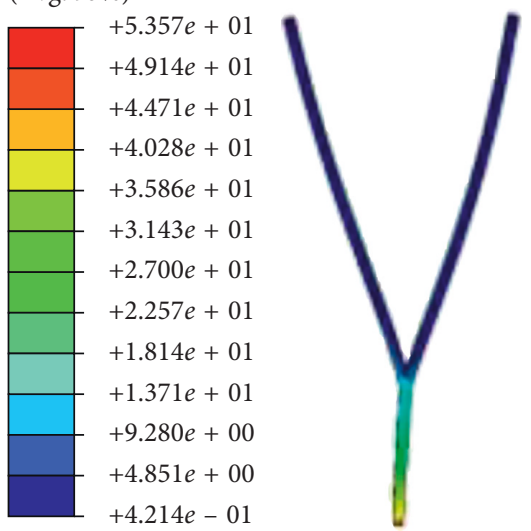

S, Mises

Multiple section points (Avg: 75\%)
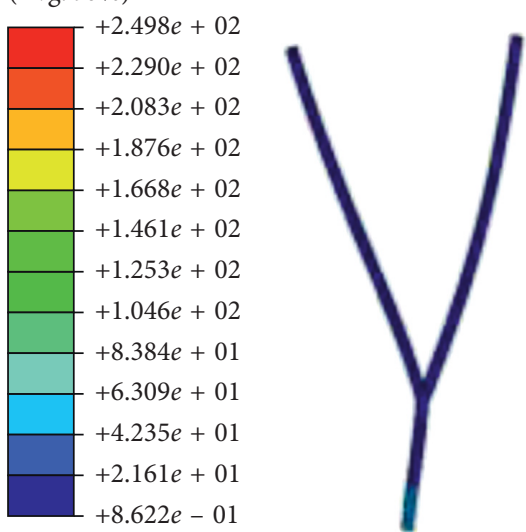

SDEG

(Avg: 75\%)

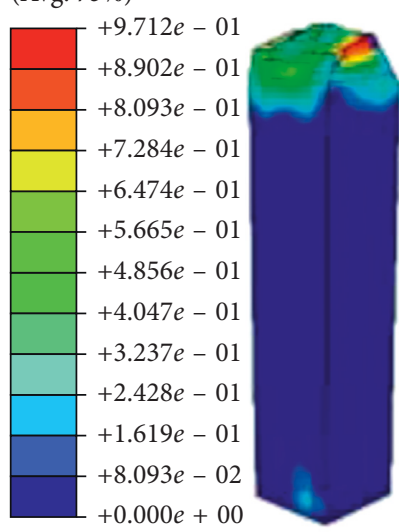

S, Mises

(Avg: 75\%)

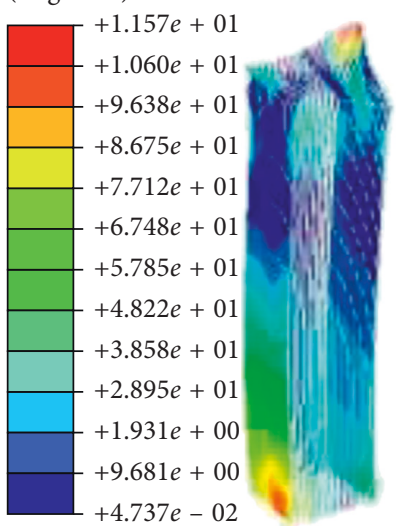

(b)
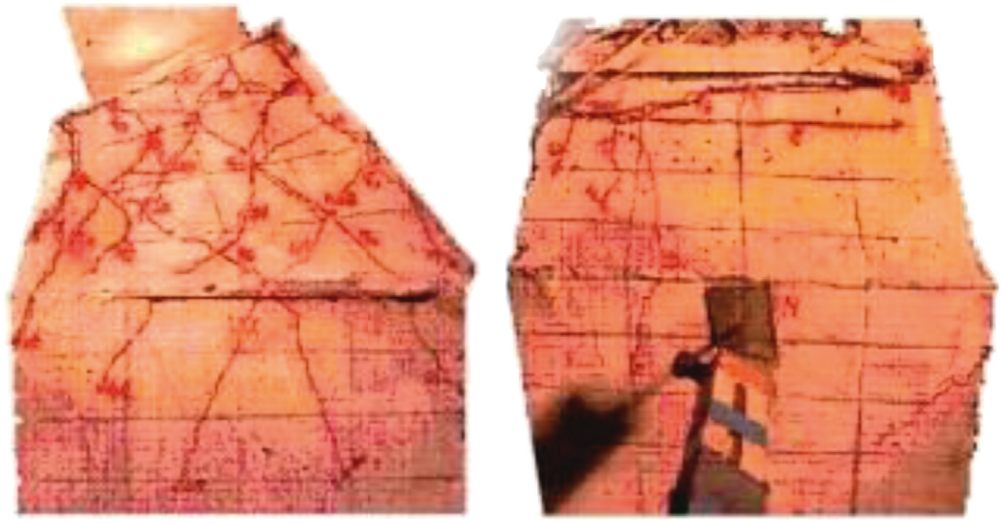

(c)

Figure 8: Damage comparisons. Calculated results in (a) case 1 and (b) case 2 and (c) test damage [2].

Under the seismic ground motion (El Centro seismic wave) with the peak acceleration of 220 gal, the calculated displacement responses of point $\mathrm{D}$ and acceleration responses of point A were compared, respectively, with test results as shown in Figure 6. The comparisons showed that the calculated results agreed well with the test results.
The global structural damage states can be described by the mechanical parameter plastic strain. Figure 7 shows the plastic strain distributions of the global structure in case 1 and case 2 , respectively. In case 1 (Figure 7(a)), the damage mainly occurred at very few beams of the second floor of the $\mathrm{RC}$ frame structure, and the maximum plastic strain was 


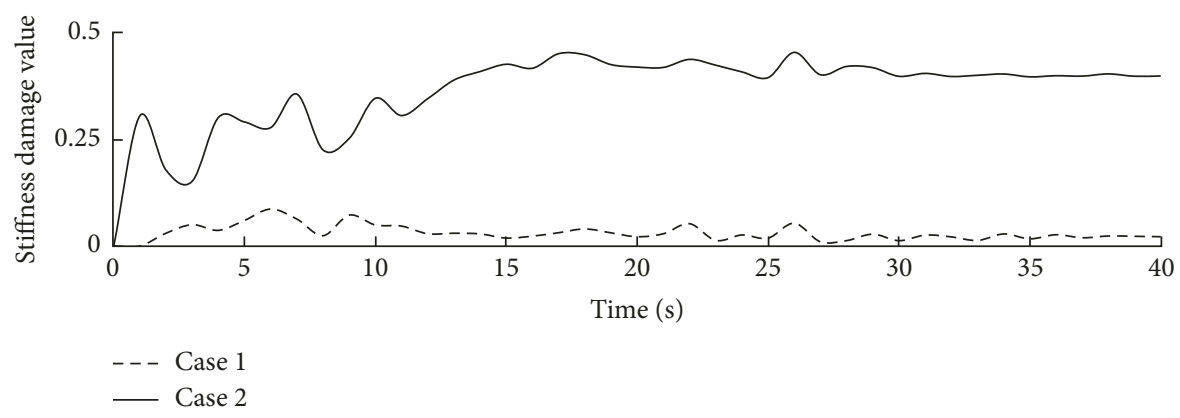

FIgURE 9: The stiffness damage evolutions of the SRC column.

about $1.638 \times 10^{-9}$. It indicates that the structure almost kept the elastic mechanical behavior global under the El Centro seismic motion with the peak acceleration of 35 gal. In case 2 (Figure 7(b)), the damage occurred at many beams of the second and third floors of the RC frame structure, and the maximum plastic strain was about $2.968 \times 10^{-4}$. It shows that the structure damaged seriously, but it probably did not collapse for almost all damages occurred at the beams of the $\mathrm{RC}$ frame.

\section{Mechanical Behavior of Y-Type S-SRC Column}

The Y-type S-SRC column was subjected to the forces from the roof by two connected points. The responses of the two points were very different under the same seismic motion. Based on the proposed local-fine FEM method, the mechanical behavior of the Y-type S-SRC column can be analyzed here. The calculated damage of the Y-type S-SRC column was compared with the test results as shown in Figure 8.

In case 1 (Figure 9), the concrete at the top and bottom ends of the SRC column damaged slightly, and the maximum damage value of concrete was 0.613 . The maximum value of the von Mises stress of the steel column was $53.6 \mathrm{MPa}$ at the bottom end. The maximum value of the von Mises stress of the longitudinal reinforcements was $43.8 \mathrm{MPa}$. It indicates that the column damaged slightly under the El Centro seismic wave with the peak acceleration of 35 gal.

In case 2 (Figure 9), the concrete at the top end of SRC column damaged seriously, the maximum value of the concrete damage was 0.971 . The maximum value of the von Mises stress of the steel column was $249.8 \mathrm{MPa}$ at the bottom end. The maximum value of the von Mises stress of the longitudinal reinforcements was 115.7 MPa. These calculated damage results agreed with the test results (Figure 9). According to the damage mode, the concrete at the top end of the SRC column could be strengthened by some structural measures in the actual engineering design.

The calculated stiffness damage evolutions of the SRC column in case 1 and case 2 were shown in Figure 9. In case 1 , the maximum stiffness damage value of the SRC column was 0.05 ; thus, it means the SRC column damaged very slightly. In case 2, the maximum stiffness damage value of the SRC column was 0.45. It means the SRC column damaged seriously but not collapsed for concrete material damage that mainly occurred on the top end and the longitudinal reinforcement did not yield. These calculated results also agreed with the conclusion from the plastic strain analysis results of the global structure.

\section{Conclusions}

In this paper, the seismic responses of a large-space vertical hybrid structure and the mechanical behavior of the Y-type S-SRC column were analyzed based on the local-fine FEM. The calculated local damage results agreed with the test results and also the seismic responses of the global structure. However, the damage states of the Y-type S-SRC are related with the material strength, its configuration, and the global structure form. Another effected factor, that is, the secondorder effect on the local mechanical details of the Y-type S-SRC column, was ignored in this paper. It shows that the proposed numerical simulation method can be used to study the mechanical behavior details of a local member of a large spatial structure.

\section{Data Availability}

The data used to support the findings of this study are available from the corresponding author upon request.

\section{Conflicts of Interest}

The author declares that there are no conflicts of interest.

\section{Acknowledgments}

The author acknowledges with thanks the support of the National Natural Science Foundation of China under the Grant no. 51778284 and the China Postdoctoral Science Foundation under the Grant no. 2016M591836.

\section{References}

[1] S. L. Dong, "Development and expectation of spatial structures in China," Journal of Building Structures, vol. 31, no. 6, pp. 38-51, 2010, in Chinese.

[2] X. L. Lu, Shaking Table Test on Pudong International Airport Terminal 2 Building in Shanghai, State Key Laboratory for Disaster Reduction in Civil Engineering of Tongji University, Shanghai, China, 2008, in Chinese. 
[3] X. D. Fang, S. Y. Li, J. R. Qian, and R. Q. Yang, "Experimental research on seismic behavior of concrete filled steel tubular column-ring beam joint under cyclic loading," Journal of Building Structures, vol. 23, no. 6, pp. 10-18, 2002, in Chinese.

[4] X. L. Lu, F. Liu, and W. S. Lu, "Shaking table model test on Pudong International Airport Terminal 2 building in Shanghai," Journal of Earthquake Engineering and Engineering Vibration, vol. 29, no. 3, pp. 22-31, 2009, in Chinese.

[5] Z. X. Li, T. Q. Zhou, T. H. T. Chan, and Y. Yu, "Multi-scale numerical analysis on dynamic response and local damage in long-span bridges," Engineering Structures, vol. 29, no. 7, pp. 1507-1524, 2007.

[6] J. G. Yue, A. Fafitis, J. Qian, and T. Lei, "Application of 1D/3D finite elements coupling for structural nonlinear analysis," Journal of Central South University of Technology, vol. 18, no. 3, pp. 889-897, 2011.

[7] J. Lublinear, J. Oliver, S. Oller, and E. Oñate, "A plasticdamage model for concrete," International Journal of Solids and Structures, vol. 25, no. 3, pp. 299-329, 1989.

[8] T. Yu, J. G. Teng, Y. L. Wong, and S. L. Dong, "Finite element modeling of confined concrete-I: Drucker-Prager type," Engineering Structures, vol. 32, no. 3, pp. 665-679, 2010.

[9] T. Yu, J. G. Teng, Y. L. Wong, and S. L. Dong, "Finite element modeling of confined concrete-II: plastic-damage model," Engineering Structures, vol. 32, no. 3, pp. 680-691, 2010.

[10] J. B. Mander, M. J. N. Priestley, and R. Park, "Theoretical stress-strain model for confined concrete," Journal of Structural Engineering, vol. 114, no. 8, pp. 1804-1826, 1988. 


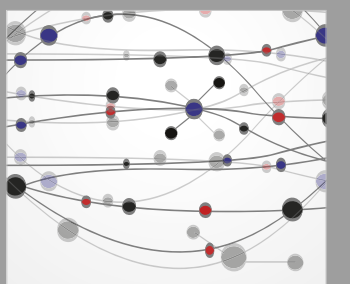

The Scientific World Journal
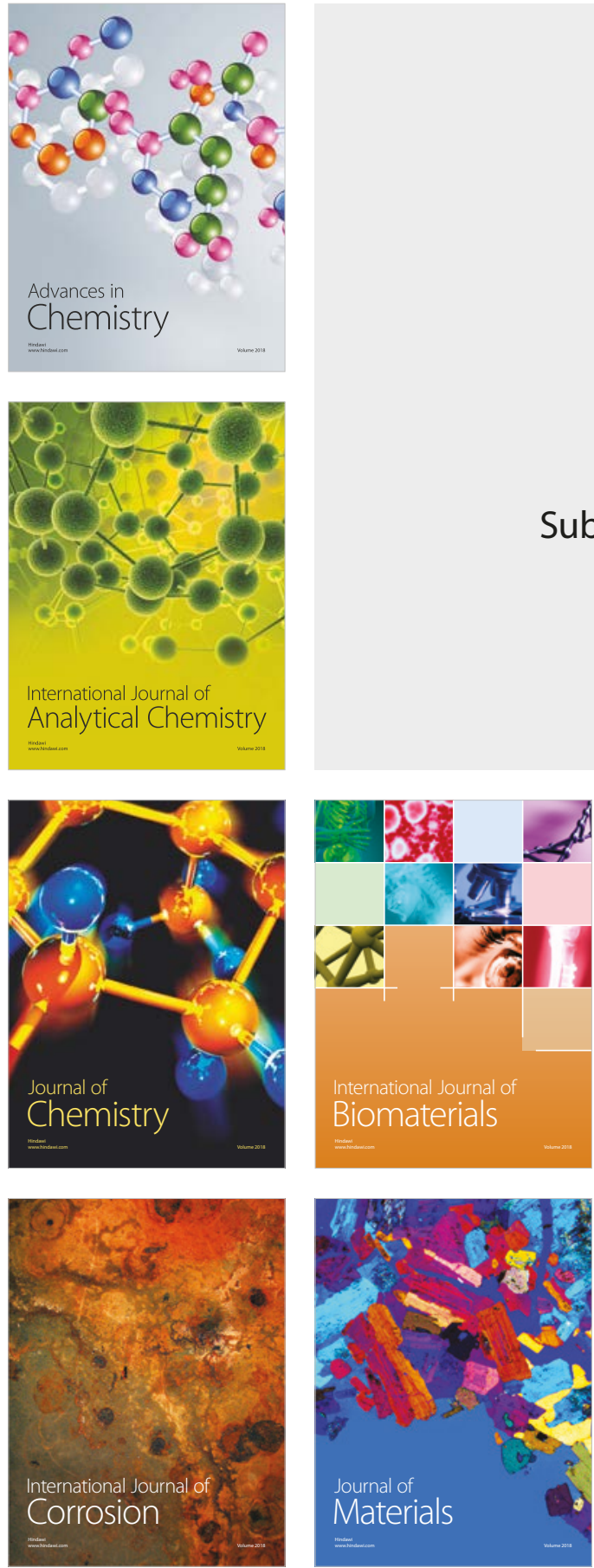

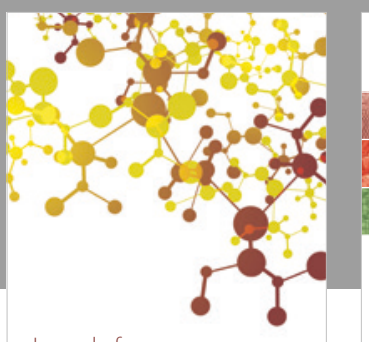

Journal of

Applied Chemistry
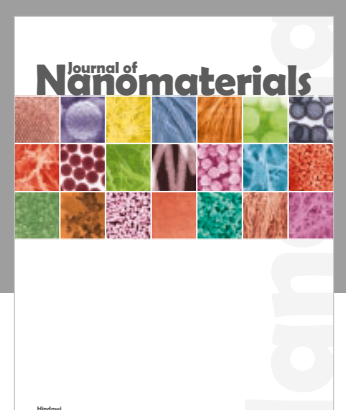

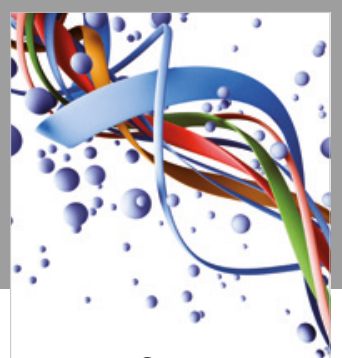

Scientifica

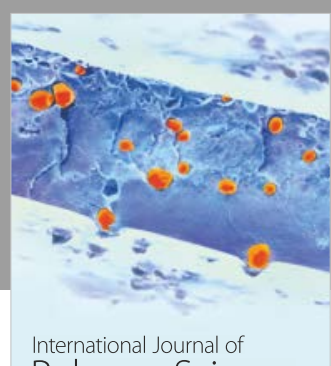

Polymer Science

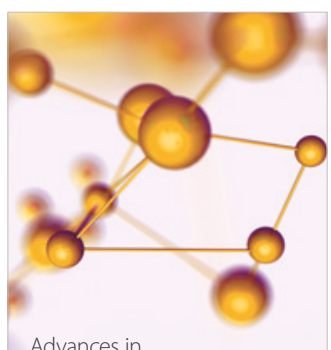

Physical Chemistry
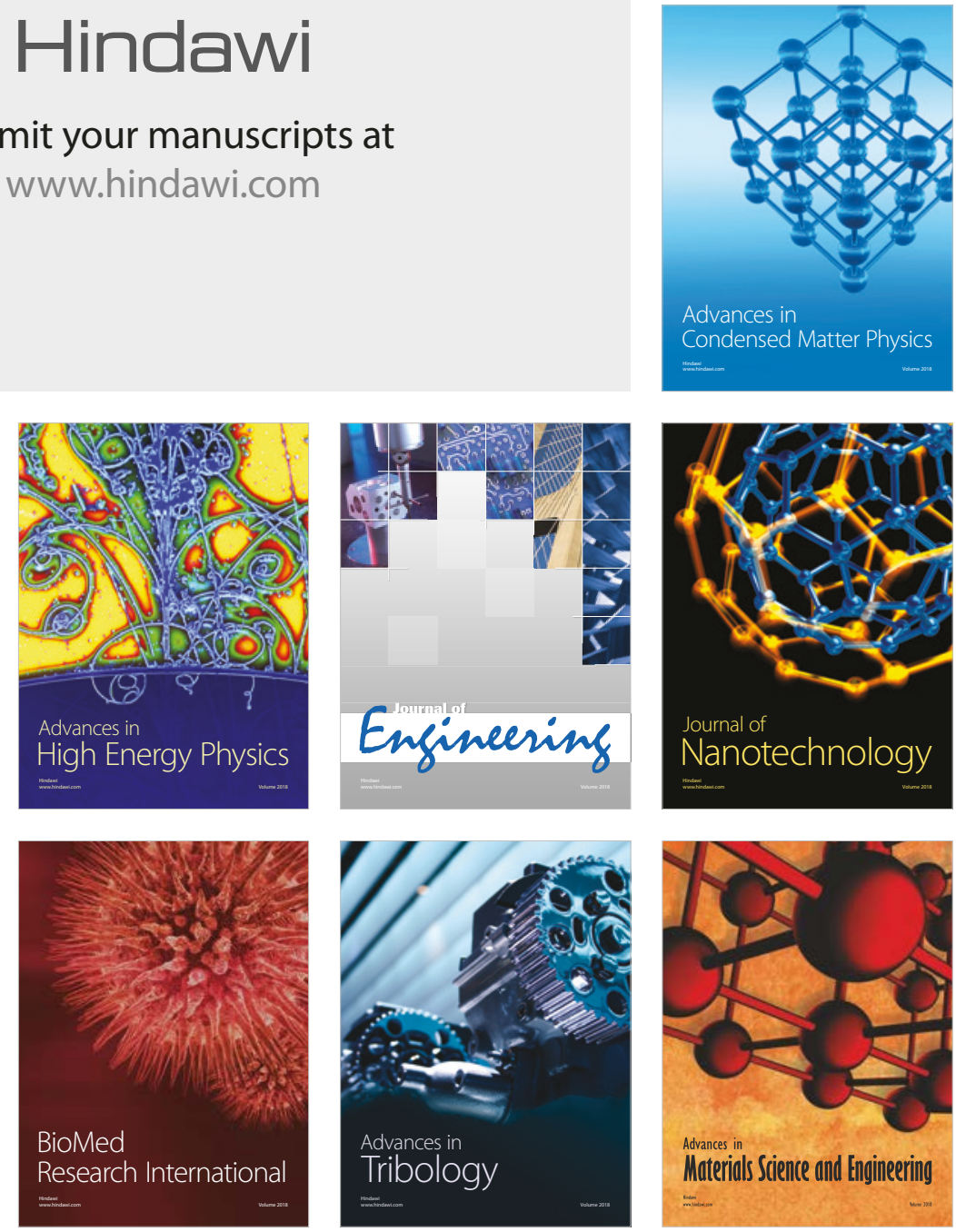